\title{
The Ultimate Digital Library: Where the New Information Players Meet
}

Andrew K. Pace, American Library Association, USA, 2003, xvii + 168 pages, ISBN 0-8389-0844-6 (paperback), £25.95

\section{George Macgregor}

\author{
Centre for Digital Library Research \\ University of Strathclyde
}

\begin{abstract}
A virtual revolution has enthralled libraries since 1993. This revolution has been both liberating and exciting for librarians and end users alike. However, like most revolutions, it has simultaneously elicited a sense of dread and disorientation amongst the LIS community as long established service paradigms and library precepts are gradually supplanted by the new revolutionary order. Indeed, the Web constitutes such an insurmountable challenge to the supremacy of 'librarians as the custodians of information' that some have remained in a perpetual state of denial since the advent of the Web. This sense of dread is, in many cases, not entirely unfounded. Not only does the Web draw into sharp focus exciting issues pertaining to the management, storage, organisation and retrieval of information, but it has facilitated and provided a vehicle for the seemingly unstoppable march of gargantuan commercial organisations with, allegedly, dishonourable motives.
\end{abstract}

The purpose of Pace's book, therefore, is to unveil the rampant schizophrenia impeding some libraries from innovating, providing superior services and, above all, remaining competitive. This essentially entails some much needed rationalisation of the trepidation blighting LIS relationships with vendors or commercial information providers. With chapters entitled, "Strange Bedfellows", "Sizing Up the DotCom Competition" and "Sheep in Wolves' Clothing", Pace's principal argument throughout Ultimate Digital Library is quite simple: libraries need to be more willing to harvest the abundant fruits blossoming in the commercial sector. The Internet and the Web constitute a huge challenge to the LIS community, and whilst librarians have many indispensable skills required for managing the burgeoning global information environment, they need to extricate themselves from outdated practices and embrace collaborative 'win-win partnerships' with vendors to truly realise improved and future conscious services. Pace makes the point quite eloquently in the preface when he writes, "Libraries have built a fine house, but they do not own it outright. In the minds of some libraries, the landlord is at the front door, the taxman is at the back, and the wolves are howling outside the windows. It's time we invited everyone in for a sleepover. Strange bedfellows, indeed, but bedfellows, nevertheless".

Pace's arguments might be nauseatingly idealistic for some, but they are extremely persuasive, authoritative, pertinent and highly informed. Although currently presiding over systems at the North Carolina State University Libraries, Pace has significant experience with such strange bedfellows as Innovative Interfaces. This experience allows him to comment with panache and authority about library-vendor relationships whilst simultaneously punctuating the book with examples rooted firmly in 
personal experience. Interestingly, such arguments have recently assumed greater relevance with Google's launch of 'Google Scholar' (http://scholar.google.com/), as well as Google's controversial move towards digitising eminent library collections (which at least indicates that the most 'future conscious' libraries are now perfectly willing to choose exceedingly strange bedfellows).

Despite the adversarial sounding chapter titles, each section succinctly explores the challenges confronting libraries, how to overcome them, and suggests radical strategies designed to initiate a mutually beneficial dialogue with private sector providers. Ultimate Digital Library also constitutes a useful handbook for those practitioners involved in radically reappraising library service delivery models. If one slight criticism could be levelled it is that Ultimate Digital Library is slightly USAcentric. This is a common complaint of ALA publications and, although understandable, ALA would be wise to ensure future publications acknowledge developments in other information rich countries also. This is not to state that Ultimate Digital Library is irrelevant for those out with the USA; quite the opposite. Many of the concepts are relevant everywhere, but such overt USA centricity simply seeks to undermine a readership that should encompass LIS professionals the world over.

In many ways, Ultimate Digital Library represents Pace's personal vision of what could be achieved if there was simply greater collaboration between two opposing sectors. This vision is harmony. And who could possibly fault such noble intentions? 